\title{
Os Anos Obscuros
}

\author{
Günter Weimer
}

Resumo

O presente trabalho trata das crfticas que têm sido feitas à arquitetura do século passado e da primeira metade do presente; analisa as caracterlsticas das arquiteturas européia e brasileira deste perfodo mostrando seus diferentes significados nos dois lados do Atlåntico.

\begin{abstract}
This paper deals with the critiques that had been made to the architecture from the last century and from the first half of the present one; it analyzes also the European and Brazilian architecture carateristics of this epoch showing their different meanings in the two Atlantic borders.
\end{abstract}

Artigo elaborado com base na Tese de Doutorado "Arquitetura erudita da imigraçáo alemă", apresentada em janeiro de 1990.

Orientador. Prof. Dr. Nestor Goulart Reis Filho. 
Se há unanimidade nalgum assunto que envolve a história da arquitetura brasileira, este é o desprezo pela produção do perlodo do historicismo que, pretensamente, teria iniciado com a vinda da "Missão Francesa" e terminado com a redenção da arquitetura através do movimento modernista, em torno da II Guerra Mundial.

Se for tomada uma obra de divulgação como a de Benjamin de R. Carvalho "Duas Arquiteturas no Brasil", o leitor paciente poderá encontrar a explicação para este fato:

A época é de manifestações de "gosto" - o terrivel "gosto dominante" de que fala Giedion - que varia com as posses do adquirente, com as formas de aquisição e com as "adaptações" dos artistas encarregados de sua reprodução ou "estilização" - o que era ainda pior... No centro começavam as construções de vulto, "italianas" e "francesas" enquanto que nos bairros, os "chalets" e as residências apalaçadas e os "florentinos", se mesclam com a arquitetura tradicional e vários "luizes". Difunde-se também o "tedesco" que aparece ao lado de prédios "bascos" e "normandos" que conseguem uma vez por outra, sobressair dos outros locais da escola francesa onde é comum perseverar o "Luiz XIV" (Carvalho, 1961, 136-7)

Talvez possa ser levantada a suspeita de que obras de divulgação não apresentem a devida seriedade. Vejamos então o que diz a este respeito o arquiteto Eduardo Knesse de Mello, um respeitável professor da história de nossa arquitetura:

Isto é o ecletismo... "carnaval de estilos"... a fantasia carnavalesca vai ser usada exclusivamente nos dias de carnaval, vai ser vestida para ser exibida no desfile da passarela do Municipal e ninguém ousaria ir ao seu consultório ou escritório com todos aqueles berloques e miçangas, num dia comum de trabalho. Nem seria permitido à aeromoça embarcar no seu Boeing 707 com sua fantasia de Maria Antonieta. Mas, na arquitetura a coisa é diferente. Tem caráter permanente, duradouro. Não se troca de casa como quem troca de roupa e o indivíduo que fantasia a sua casa, seu prédio de apartamentos, sua fábrica, sua escola vai passar o resto da vida fazendo-de-conta que está vivendo em outra época, fingindo que é outra pessoa, que viveu em outro século, em outro lugar. (Mello, 1983, vol. 11, 15-9)

Acontece, porém, que nenhum dos dois tem a credencial de pesquisador. Para dirimir eventuais dúvidas de algum cético pertinaz poder-se-ia consultar a opiniāo de uma autoridade "acima de qualquer suspeita" como Luis Saia. Eis a opiniāo do mestre sobre a arquitetura do perlodo:

A licenciosidade estillstica que invadiu a arquitetura urbana no fim do período cafezista parece bastante significativa na recusa de eleição de uma forma preferida.. Mesmo a Semana de Arte Moderna que foi a manifestação mais inteligente desta fase, não chegou a se definir por uma direção preferencial... Os arquitetos deste periodo, mesmo os mais dotados, nāo conseguiram escapar da endemia. Dubugras, por exemplo, fez de tudo; Barry Parks, apesar da sólida formação profissional, foi contaminado. Esses e mais Ekman, nos coloniais ou art-nouveaux que fizeram, ou nos bairros jardins, se limitaram a copiar ou repetir, sem o menor indlcio de querer interpretar os acontecimentos que viviam a sua volta. (Saia, 1972, 219)

Outro pesquisador igualmente respeitado, o professor Paulo Santos, ainda que se exprimisse de forma mais benevolente, traçou um panorama que não deixa de ser menos preocupante. Depois de relatar as vicissitudes da abertura da avenida Central e do Concurso Internacional de Fachadas em que a firma construtora incumbida das obras colocou no edital apenas a largura dos lotes e os gabaritos legais, o autor conclui:

A preocupação maior era a da variedade, seguindo-se a inspiração vinda de fora... Nesse mostruário de estilos em que se misturavam as características do século findo e alguns remanescentes do perlodo Colonial, as vilas francesas, os villinos italianos... e 
ainda as casas de estilo internacional feitas de tijolinhos com os cunhais salientes de massa e bossagem... inclufam-se esporadicamente o estilo Neogótico (ou Neoromânocogótico) e os orientais. (Santos, 1981, 79-82)

A nivel internacional, os conceitos são muito parecidos. Para tomar um exemplo, citamos a alentada obra de Ives Bruand (1981), que não só tem a seu favor a extensão da pesquisa como ainda o aval de um doutorado na Universidade de Lille, na França.

... não só é diff́cil citar um único êxito do ponto de vista estético, como também parece que os arquitetos e construtores rivalizavam-se numa incrivel competição de feiura. São bem variadas as razōes deste fracasso total. Uma das causas principais era, com certeza, a falta de gosto e, na maioria dos casos, a falta de conhecimentos arqueológicos dos responsáveis... Os arquitetos, então, tinham de criar suas próprias soluções - 0 que evidentemente era catastrofico quando se tratava de profissionais medlocres, que não se destacavam por seu talento natural. (Bruand, 1981, 42-3)

Segundo o autor, a mediocridade e a falta de imaginação tomou conta de toda a nação, razão pela qual não há o menor interesse em examinar as peculiaridades de outros centros.

Ora, se os argumentos da autoridade francesa se sobrepõem aos dos historiadores e crfticos nacionais, deve ficar evidente que a fase entre o barroco e o moderno continua a ser tido como o perfodo negro da arquitetura nacional.

\section{Uma Concepção posta em Questão}

Apesar da ampla aceitaçāo destes preceitos, estes argumentos dificilmente podem ser sustentados. Como explicar que os arquitetos nacionais, que foram tão criativos, durante os primeiros trezentos anos de nossa história e nos últimos cinqüenta, no lapso de cento e cinqüenta anos fossem acometidos de total esterilidade de imaginação plástica? Como entender que, de uma hora para outra, toda a nação aderisse ao despropósito neoclássico? Que estranho fenốmeno conseguiu realizar o milagre do nivelamento da expressão arquitetônica num pals que os europeus chamam de terra de contrastes? (Bastide, 1971)

Inconseqüências tão flagrantes não haveriam de passar desapercebidas a todos os autores. Lemos já assinalou que o emprego dos estilos não ocorreu de forma totalmente arbitrária:

Quanto à intenção plástica, ou melhor, quanto à eleição do estilo a ser empregado nas construçōes paulistas, já insinuamos ter havido mais critérios, um relativo às construçōes oficiais e outro ligado às residências particulares.. As construçōes oficiais.. eram concebidas dentro das liçōes acadêmicas ligadas à 'caracterologia dos edifficios'... As ricas mansões... se sujeitavam aos ditames inflex'veis dos estilos eleitos pelo pensamento vigente... As casas, digamos populares... tinham seus estilos profusamente determinados sem policiamentos maiores. (Lemos, 1985, 102)

Semelhantes anotações já haviam sido feitas por Bruand (1981, 35), porém, Lemos apresenta um argumento diametralmente oposto à opiniăo daquele autor quando diz:

Na verdade, somente se aliou essa miscelânea estillstica... com o progresso, com a abastança, com a liberdade de escolha, como se a obediência a um só estilo fosse sinal de atraso próprio de outras épocas. Agora, tudo era uma questão de imaginação. (Lemos, 1979, 116) 
Assim, Lemos entende que, em vez de um embotamento, o profuso emprego de estilos estava associado à riqueza e, principalmente, ao livre arbftrio e à criatividade. Se antes, o pecado era a falta de imaginação, agora passou a ser o seu excesso.

Porém o autor que mais se diferencia dos até aqui citados é Reis Fo. Em vez de se preocupar com manifestaçōes puramente formais, baseia sua análise nas transformaçōes sociais e nas modificaçōes dos modos de produção. Em vez de iniciar sua análise com a vinda da Missão Francesa, o autor mostra que o fator mais importante foi a abertura dos portos que veio a integrar o pals no mercado mundial em conseqüência do que foi possibilitada a importação de equipamentos e conhecimentos. Com isto teria havido um notável progresso arquitetônico:

As residências... eram enriquecidas com um jardim ao lado. Esta novidade que vinha introduzir um elemento paisagistico na arquitetura residencial, oferecia a essa amplas possibilidades de arejamento e iluminação, até entāo desconhecidas nas tradiçōes construtivas do Brasil... Em todos os tipos, porém, suprimiram-se as alcovas, com evidentes vantagens higiênicas. $O$ aperfeiçoamento dos hábitos higiênicos coincidia com a instalação dos primeiros banheiros com água corrente e com o aparecimento das venezianas. (Reis Fo, 1970, 37-50)

Mesmo que o autor reconheça que esta arquitetura teve lados positivos, não deixa de assinalar suas reservas pelo emprego de formalismos ultrapassados.

Mas o autor ainda vai além. Apresenta dúvidas sobre a forma como é interpretada a origem do movimento modernista no Brasil sobre o qual conclui que:

... estamos convencidos de que somente quando se estuda o Neoclássico e o Ecletismo através de suas motivações locais é que se pode compreender de que modo, menos de quatro décadas após o final do século XIX, já era possível à arquitetura brasileira iniciar o grande avanço que a tornou conhecida mundialmente. (Reis Fo, 1970, 187)

A existência de concepçōes antagônicas a respeito da arquitetura do séc. XIX e da primeira metade do presente, constitui-se num problema de incontestável relevância e justifica o presente trabalho e o desafio lançado pelo professor Reis Fo de que o estudo das motivaçöes locais poderá fundamentar o entendimento do movimento modernista serve de razão complementar.

\section{O Neoclássico e o Eclético}

Como se percebe, não há unidade na conceituação dos estilos entâo em voga. A maioria dos autores nacionais aceita e emprega o termo "neoclássico" para definir a primeira fase do perlodo que, pretensamente, se iniciou com a vinda da Missão Francesa, em 1816, e que se teria caracterizado pelo retorno a formas da antigüidade greco-romana. Diante de confrontaçōes com novas tendências que preferiam um retorno a formas medievais e/ou bucólicas, geralmente designadas por "neogótico" e "romântico" a linguagem teria evolufdo para o "ecletismo".

Ainda que o uso dessas terminologias seja consensual, seu emprego não é isento de ambivalências. Por isto é necessário examiná-las separadamente.

Vejamos inicialmente o "neoclassicismo". Lemos assinala que:

... desde o final do século anterior (i. é, seculo XVIII), aqui e ali, já se tentava construir segundo a nova moda européia - mas construla-se "de ouvido" sem conhecimento exato das regras, ou, então, atinha-se a certos hibridismos, onde não se abandonava de vez os pormenores barrocos. (Lemos, 1979, 108) 
O legftimo "neoclassicismo" somente se teria implantado no Brasil a partir da vinda da Missāo Francesa através do arquiteto Grandjean de Montigny, conforme assinala Bruand $(1981,33)$. Santos, no entanto, afirma que, nos trabalhos daquele arquiteto predominavam as influências da Renascença e da arquitetura francesa de princípios do século XIX. (Santos, 1981, 52) Bruand insiste ... o que se convencionou chamar de neoclassicismo, na realidade não passa de uma forma de ecletismo. (Bruand, 1981, 33)

Se no Brasil o Neoclassicismo desde o começo foi "eclético" cumpre examinar se é procedente a suposição de Bruand de que tenha existido um "verdadeiro neoclassicismo" na Europa. A este respeito escreve Benevolo:

o Classicismo, no momento em que chega a ser precisado cientificamente, torna-se uma convenção arbitrária e transforma-se em neoclassicismo... convenção por convenção, o mesmo tratamento aplicado a todo tipo de forma do passado, àquelas medievais, exóticas, etc., produzindo os respectivos 'revivals': o neogótico, o neobizantino, o neo-árabe, e assim por diante. (Benevolo, 1976, 29)

Isto mostra que os próprios europeus reconhecem que não existiu um estilo "neoclássico verdadeiro" e que o mesmo esteve transpassado de "ecletismo" desde o nascedouro.

Com o conceito de "ecletismo" acontece algo semelhante. As definições encontradas em dicionários indicam que se trata de um método filosófico que caracteriza por não seguir apenas um sistema único, mas em adotar dentre os diversos sistemas o que for julgado como sendo o melhor. Isto, por extensão, também acabou por ser aplicado à literatura e às artes. Ora, esta é uma definição que caracterizada por sua própria negação (não seguir sistema algum), o que, por si só, a invalida. Além do mais, não é precisa em sua aplicaçāo ao movimento arquitetônico do fim do século passado e do começo deste porque nele houve uma definição pelo uso de linguagens históricas.

\section{As Bases Sociais de uma Nova Estilistica}

A partir da segunda metade do séc. XVIII a Europa foi sacudida por um movimento que haveria de transformar o mundo inteiro: a Revolução Industrial. O ouro e a prata encontrados na América permitiram que a Peninsula Ibérica vivesse num fausto como até então não houvera notícia. Seus governos, no entanto, não souberam tirar proveito da inesperada riqueza e se lançaram num consumismo perdulário. Decretando até quinze feriados por mês, a Corte de Lisboa julgara ter entrado numa bem-aventurança, na qual o trabalho produtivo havia se tornado supérfluo. Para acalentar o delirio da riqueza e da vida descomprometida, comerciantes ingleses traziam todo o gênero de mercadorias e desta forma carreavam enormes fortunas para a Inglaterra que encontrou al os fundos que financiaram a sua Revoluçāo Industrial. (Paula, 1971 e Chantal, s. d.)

São conhecidas as dramáticas condiçōes em que este processo se desenvolveu. Seria, porém, conveniente lembrar que o súbito enriquecimento da Inglaterra foi conseguido às custas de um alto preço pago pelas classes proletárias que tentavam sobreviver na mais negra miséria. A seu lado foi-se formando uma nova classe social que na época foi chamada de "burguesia", hoje denominada de "empresariado" Esta classe começou por alinhar em seu seio pessoas originárias das diversas classes pré-existentes. Como os empreendimentos industriais tinham uma estrutura muito complexa em que o capital se conjugava com a inovação técnica e o comércio através de influências polticicas, normalmente os novos empreendimentos eram capitaneados por artesāos inovadores, comerciantes ricos e nobres influentes. A nova classe conquistou tamanha riqueza e tanto poder que passou a se constituir num fenômeno único no mundo de então. Po- 
rém, ela carecia de um passado histórico do qual a nobreza, sua maior rival, se orguIhava e cultivava com extrema dedicaçăo.

Para fazer frente ao problema, os empresários criaram uma salda mágica: como eles haviam criado um império que suplantava todos os que haviam existido até então, apropriaram-se do maior de todos quanto havia notícia, o império da Roma antiga. Enquanto este alimentava as fantasias dos novos donos do mundo, a frugalidade da vida na Grécia clássica servia de modelo ao puritanismo oficial.

Estas foram condiçōes que levaram ao surgimento de pensadores que promoveram uma apaixonada revisão das culturas greco-romanas das quais Johann Joachim Winckelmann se tornou o mais conhecido. Sua obra mais famosa é "Gedanken über die Nachahnung der griechischen Werke in der Malerei und Bildhauerkunst" que foi traduzida para o português com o nome de "Reflexōes sobre a arte antiga".

O que liga Winckelmann ao passado grego não é a realidade material de sua história, mas sua estética, um sonho que se concretiza na imitação de um ideal. Dal a importância de seu conceito de imitação: O único meio de nos tornarmos grandes e, se possível, inimitáveis, é imitar os antigos. (Winckelmann, 1975, 39-40)

Este conceito facilmente pode levar a más interpretaçōes. Segundo Winkelmann, o único caminho para nos tornarmos grandes e, se possivel, tão inimitáveis como os antigos eram inimitáveis, é a imitação dos antigos. À primeira vista esta afirmação contém uma contradição (a imitação do inimitável). Mas a mesma só existe se tomarmos a imitação no sentido da cópia. Para o autor, esta imitaçāo deveria almejar o belo universal e suas imagens ideais em conformidade com os artistas gregos. Portanto, o sentido desta imitação não é naturalista ou realista, mas platônica. Não se trata, portanto, de simplesmente copiar os antigos, e sim em pensar como os gregos, em comportar-se como eles, exigindo da arte uma missão semelhante a dos gregos.

Foram os ingleses que primeiramente fizeram uso de semelhantes teorias na arquitetura e o mesmo se espalhou rapidamente pelo resto da Europa.

Em fins do sec. XVIII manifestou-se uma reação contra esta concepção teórica, alimentada pelas facçōes mais conservadoras da sociedade inglesa, especialmente, do clero e da nobreza. Em lugar da imitação do mundo greco-romano, aspirava-se a revivificação do passado glorioso destas mesmas classes, ou seja, da idade média. A personalidade que mais tem sido identificada com este movimento não foi um arquiteto, mas um clérico. John Ruskin abriu sua bateria contra os modos de produção fabril porque via neles as causas de todos os males sociais.

Nesta concepção não encontramos mais aquela busca platônica de um ideal de beleza como em Winckelmann: basta destruir todas as formas fabrís de produção que, automaticamente, a humanidade se reintegraria com a arte.

A verdade é que a linguagem apocalíptica de Ruskin sensibilizou larga faixa da sociedade e muitos arquitetos se lançaram numa profunda revisão da arquitetura gótica. Esta concepção acabou por suscitar grandes discussōes em torno do tema sobre a pertinência de cada estilo aos diversos tipos de programas arquitetônicos. Os resultados são facilmente previsiveis: se a questão era reviver o passado, por que o mesmo teria de se limitar à dualidade classicismo/goticismo?

Lützeler mostra que o breve modismo hegemônico do neogótico foi acompanhado da valorização de outras manifestaçōes estillsticas: o egípcio, o românico, o protocristão, o gótico e o renascimento. (Lützeler, 1953, 230-1) Com um pouco de boa-vontade o autor teria podido ampliar ainda mais sua lista. A variedade de tantos modelos criou novos pressupostos dentre os quais cumpre destacar a possibilidade de escolha dentre as 
diversas opçöes e a conseqüente necessidade de harmonizar entre si as diversidades das soluçōes possiveis. Estas polaridades levaram a sérias reflexōes sobre a criatividade que, portanto, já entrou em pauta muito antes de que os modernistas desfraldassem a sua bandeira na cruzada contra a "heresia historicista"

De tudo isto se conclui que a proposta de Ruskin e seus seguidores, de programar uma volta ao passado, na realidade, foi um tiro que saiu pela culatra ao criar os pressupostos que levaria à conquista de uma liberdade criadora até então não imaginada. Tem sido lugar comum na crftica européia o ceticismo com que vem sendo encarado este perfodo. Afinal qualquer imitação não deixa de ser uma imitação. $O$ que tem sido esquecido que este foi o preço que teve de ser pago por uma conquista necessária e indispensável para que pudesse ser dado o passo seguinte, qual seja a derrubada das barreiras impostas pela idealização do passado. Esta seria a grande conquista do modernismo.

\section{O Historicismo no Brasil}

Como pals periférico e colonializado, dificilmente aqui acontece qualquer fato importante, cujas causas não sejam atribuídas a fatores externos. Para que houvesse alguma renovação na arquitetura, admite-se como óbvio que alguém tenha vindo de pals central e tenha feito o favor de nos civilizar. Assim, é que unânime a aceitação de que o historicismo tenha sido aqui implantado pela Missão Francesa que veio em 1816 a convite de D. João VI. Todas as honras pela introdução do novo estilo são dadas ao arquiteto Auguste Henri Victor Grandjean de Montigny. No entanto, a existência de arquitetos contemporâneos como João da Silva Moriz, Pierre Josef Pézérat (contratado por Pedro I como seu arquiteto particular, no dizer de Santos, 1981, 55), Pedro Alexandre Cavroé (o arquiteto da cidade, como reconhece Reis Fo, 1941, 159), Joaquim Cândido Guillobel, Julius Friedrich Koeller e Charles-Philipe Garçon Riviére está a demonstrar que Montigny não era o único entendido no off́cio.

Porém, ainda está em aberta a questão do pioneirismo de Montigny no emprego do historicismo entre nós. Com injustificável atraso começa só agora a ser citado o nome de Giuseppe Antonio Landi (1708/90) apesar de que Mello Jr. já em 1973 havia feito a seguinte afirmação:

Antes de Grandjean nascer, Belém já vira construir o Palácio dos Governadores, a velha Sé, a capela de S. João Batista, as igrejas de Sant'Ana e do Carmo, a capela do Murutucu e a fachada das Mercês. Enquanto a sede da Colônia e as Capitanias de Minas, Bahia e Pernambuco viviam o fastlgio da Arte Barroca, Belém conhecia as tendências puristas de um novo classicismo de origem italiana... (Mello Jr., 1973, 4c)

Efetivamente, Montigny nascera em 15/07/1776, quando o projeto mais conhecido de Landi, o do palácio do governo, já completava dez anos. Por vezes cita-se um regresso à influência romana quinhentista, como é o caso da arquitetura da (igreja) Santa Cruz dos Militares no Rio de Janeiro (Barata, 1983, 381) obra do brigadeiro e arquiteto José Custódio de Sá e Faria ou a igreja da Candelária (Santos, 1981, 52) projeto do igualmente brigadeiro e arquiteto Francisco Joăo Roscio. (Maurfcio, 1947, 74 e Esteves, $1930,11)$ Santos cita ainda a Associação Comercial de Salvador, Bahia costrufda em 1811 a partir de um projeto de Cosme Damião da Cunha Fidié e o teatro São João no Rio de Janeiro, construído no mesmo ano e de autoria de Manoel da Silva. (Santos, 1981, 52 e 54) Ainda foram encontradas referências das igrejas de S. Francisco de Paula (Santos, 1981, 52) e do Carmo, no Rio de Janeiro, bem como a obra do mestre Valentim da Fonseca e Silva (Barata, 1983, 382). Barata cita um projeto de um teatro para S. Luiz do Maranhão e Bardi $(1979,53)$, o Teatro São João, de Salvador, Bahia. 
Ora, se há tantos exemplos historicistas realizados antes de 1816 é diffcil entender a razão da insistência em atribuir o pioneirismo a Montigny.

\section{As Condições da Implantação do Historicismo no Brasil}

Como foi visto, o historicismo se desenvolveu na Europa devido a uma revolução social, produtiva e polftica. Sempre esteve associado com movimentos de expansão econômica e de centralização autoritária do poder.

Eram estas as condiçōes encontradas no Brasil? Claro que não! A chamada "vinda da famnia real" na realidade não passava de uma fuga de seu próprio pals, única alternativa para escapar de uma derrota certa. Para a corte, o clima era de degredo e consternação. A liberalização do comércio internacional foi uma imposição das circunstâncias e nada tinha a ver com as revoluçōes que estavam se desenvolvendo na Europa. Para a Colônia a abertura dos portos teve o significado de uma concessão e não de uma conquista.

De forma semelhante o grande avanço polftico, proveniente da chegada da famflia real, nāo se processou por imposiçōes internas, mas resultou de contingências européias. Se é certo que uma das conseqüências desta vinda foi a independência, também é verdade que, sem as amarras de um colonialismo polftico, calmos noutro, o econômico: todo o espalhafato da declaração da independência serviu apenas para comemorar a troca de dono, de Portugal pela Inglaterra.

Por tudo isto se percebe que a opção pela arquitetura chamada neoclássica se processou sem uma base material correspondente. Isto já acontecera antes, com o barro$\mathrm{Co}$, que foi trazido pela contra-reforma sem que aqui houvessem protestantes e tornaria a acontecer mais tarde, com o modernismo que se afirmou sem uma base proletária.

Um segundo aspecto a ser destacado é que este questionamento começou a ser colocado em discussão com uma defasagem de cerca de cinqüenta anos. Isto teve conseqüências que não podem ser descuradas. Ao tempo da oficialização, ou seja, do emprego desta linguagem, por parte do governo, os palses centrais já tinham realizado obras dentro das novas concepçōes. Em conseqüência, as realizaçōes que passaram a ser feitas no Brasil tiveram por modelo não os originais greco-romanos mas os neo-europeus. Noutras palavras, nossa produçāo foi a imitação da imitação. Assim, Santos $(1981,52)$ vê as influências de Robert Adam no ediffcio da Associação Comercial da Bahia e observa que o teatro São Joăo apresentava semelhanças com o de São Carlos de Lisboa. Aos céticos, isto poderia significar apenas a demonstraçāo de nosso atraso cultural. Para nós, foi o preço pago por nosso alinhamento da cultura ocidental. Noutros termos, significou um grande avanço no processo civilizatório.

Como foi visto, anteriormente, na Europa, a evoluçāo da linguagem formal foi devida ao confronto com o gótico, o que tem levado autores apressados a insistir nesta tese referindo-se ao Brasil. Isto tem fundamento?

A fase gótica da arquitetura portuguesa é rala em realizaçőes porque neste perlodo a Península Ibérica estava dominada pelos mouros. Por isto esta linguagem teve pouco significado dentro da tradição lusa. Logo não seria de esperar que este estilo despertasse a "inspiração" dos arquitetos no pals.

Está claro que tivemos a nossa fase neogótica. Nossas igrejas do estilo são, quase todas, deste século o que demonstra que a lógica da evoluçāo na Europa muito pouco tem a ver com a da arquitetura nacional. 
As discussōes acadêmicas se centraram na questão do estilo. Com isto são esquecidas as inovaçōes técnicas introduzidas na arquitetura. Reis Fo já chamou a atenção para a importância da introdução de novos materiais e procedimentos na construçăo. Paralelamente a isto, houve uma reformulação do uso dos ediffcios. A utilização do andar térreo por parte das famfias, a implantação de um jardim lateral que possibilitaria a abertura de janelas para ventilação e iluminação das alcovas representaram avanços bem mais significativos que as inovaçōes estéticas. (Reis Fo, 1970, 120-2) Estes fatores, certamente, vão explicar a grande divulgação destas inovações por todo o pals. 0 mesmo autor ainda assinala que a base destas transformações arquitetônicas são encontradas na imitação que a nobreza rural promovia em seus estabelecimentos interioranos, a partir dos modelos implantados na Capital. (Reis Fㅇ, 1970, 140-1)

De tudo isto pode-se concluir que a implantação do historicismo atendeu às necessidades emanentes das transformações supra-estruturais, conquanto a infra-estrutura permanecia pouco flexlvel. As tensōes resultantes de imposiçōes da conjuntura internacional acabaram por criar as condiçōes reformistas que procuraram adaptar as inovações arquitetônicas européias a uma estrutura social arcaica. Esta contradição explica a superficialidade com que as teorizaçōes dos paises centrais foram aplicadas no Brasil, fazendo com que elas acabassem por ser reduzidas quase a um modismo. Pelo lado inverso, a aceitação destes "modismos" fez com que os métodos produtivos se modernizassem: os produtos importados trouxeram consigo novas concepções tecnológicas que tiveram de ser absorvidas e que, neste processo, acabaram por criar as condiçōes que levaram a transformaçōes mais profundas na própria arquitetura. Assim a superficialidade cenográfica apresentada, na realidade, esconde transformaçōes estruturais imperceptfveis a um contato apressado como o melhoramento das condições de habitabilidade e a racionalização do uso das construções. Estas condições săo de fundamental importância para o entendimento da segunda fase do historicismo brasileiro, quando, ao contrário do primeiro, se manifestaram algumas transformaçōes infraestruturais.

\section{O Período Áureo do Historicismo Brasileiro}

A fase do historicismo ortodoxo terminou com a Regência. Até então o pals passou pelas vicissitudes da volta da Famnia Real, da declaração da Independência, das disputas pelo poder das quais resultou o golpe do Imperador impondo uma constituição autoritária, das arbitrariedades de Pedro I, que resultaram em sua abdicação em favor de seu filho de cinco anos de idade e da instauração do perlodo regencial que se caracterizou por sua instabilidade e pelos movimentos armados que assolaram o pals. A romântica coroação de um imperador de quinze anos obviamente não haveria de pôr a casa em ordem. O pals continuava convulsionado e nem liberais nem conservadores conseguiam se firmar no poder. Certo é que a partir da metade da década de 1840 a nação entrou em calma relativa até o ano de 1850, quando o governo inglês impôs, sob ameaça de canhoneiras, a definitiva abolição do tráfego de escravos já que os tratados anteriores foram inefetivos. A lei de proibição da importação de mão-de-obra servil, que se tornou conhecida com o nome de Eusébio de Queirós, acabaria por reter no pals os capitais que flulam para a mão dos traficantes ibéricos e propiciaria um desenvolvimento como a nação até então nunca vivenciara. (Hollanda, 1976, 44-5) Estes capitais foram a primeira grande oxigenação da economia do pals.

Evidentemente, a abolição do tráfego negreiro não significou a abolição da escravidão. A produção ainda continuou a ser escravista. Porém, a impossibilidade da reposição de mão-de-obra importada fez com que seus preços disparassem. A partir de então os cativos passaram a ser adquiridos nas regiōes de economia mais precária, fazendo ali 
aparecer sintomas evidentes de que o regime escravocrata estava com seus dias contados.

O comércio internacional e os presupostos da livre iniciativa forneceram a munição para acabar com o regime escravocrata nos centros hegemônicos, pois as formas tradicionais de produção não se coadunavam com a dinâmica exigida pelas relaçōes internacionais e demonstravam a sua inviabilidade econômica. Ainda que as forças conservadoras fizessem todo o possivel para manter esta forma de trabalho, a verdade é que a interrupçāo do tráfego foi o primeiro ato de uma paulatina abolição do regime. Tanto isto é verdade que se conseguiu acabar com ela somente depois de quatro décadas de lutas. Devido a estas pressões, as forças conservadoras acabaram por "conceder" certas liberalizações como a lei do ventre livre, através da qual se descartavam do ônus de sustentar os filhos de escravas e a do sexagenário que concedia a liberdade ao escravo quando o mesmo chegasse aos sessenta anos, desde que trabalhasse mais cinco anos para "indenizar" seu dono pelos "prejulzos" advindos da sua libertação. Por esta "concessão" os escravocratas descartavam-se dos encargos de sustentar os escravos improdutivos.

Na medida em que os escravos lam sendo "libertados", foram substituldos por mão-deobra livre de origem imigrantista. Neste processo, pôde-se verificar que o regime de trabalho assalariado apresentava uma série de vantagens em relação à escravidão: não exigia investimentos iniciais (como a compra do escravo), não havia despesa com a manutenção da mão-de-obra, o que era especialmente importante nos perlodos de entre-safra ou na época de retraçāo do trabalho sazonal e, principalmente, apresentava maior produtividade.

Nestas condições estavam criadas, em meados do século, as duas premissas que definiriam os caminhos da arquitetura a partir de então: a existência de capitais e uma mudança nas relaçōes de trabalho.

$\mathrm{Na}$ literatura técnica, este perfodo é conhecido por ecletismo que se caracteriza por apresentar soluçōes que, mesmo que vinculadas ao historicismo europeu, não encontram modelos paradigmáticos no Velho Continente como o chalé e a casa de entrada lateral, onde a influência do romantismo é por demais evidente, porém o fato de nāo haverem sido encontrados os figurinos destas manifestaçōes evidencia que, em certa medida, o cordão umbilical já estava sendo cortado.

\section{O Neocolonial}

O passo seguinte a ser dado em direção a uma consciência nacional foi a adoção do estilo neocolonial. $U$ centro de irradiação deste movimento foi a cidade de São Paulo e a personalidade colocada no centro dos acontecimentos foi o engenheiro lisboeta $\mathrm{Ri}$ cardo Severo da Fonseca Costa. Formado na cidade do Porto em 1891, teve de abandonar seu pals por ter tomado parte num frustrado movimento republicano. Seu nacionalismo o levou à pregação da teoria de que, se a arquitetura devesse imitar o passado, que este fosse do próprio pals. Esta pregaçāo, no entanto, não teve maiores repercussōes, até que fatos novos vieram a dar outros rumos a suas teorias: a l Guerra Mundial e as comemoraçöes do centenário da Independência. Em verdade Victor Dubugras em São Paulo e Heitor de Melo no Rio, vinham empregando o novo estilo desde a 1 Guerra, mas foi no médico e crítico de arte José Mariano Fo que o movimento encontrou seu "condottiere" e divulgador. Num ardor evangélico, incentivou as artes em geral e a arquitetura em particular, promovendo debates e concursos, liderando associaçōes de artistas, escrevendo artigos e livros, enviando pesquisadores para as fontes primárias coloniais, conseguiu transformar a arquitetura numa espécie de "causa de nacionalida- 
de", muito embora sua repercussão se limitasse, inicialmente, apenas ao centro-sul. Sua obstinação teve por conseqüência uma grande aceitação do estilo, tanto por parte do público como dos arquitetos e sua influência se fez sentir até na década de 60.

Tem-se discutido a originalidade e a importância deste movimento. Na verdade, toda a sua pregação está perfeitamente de acordo com os paradigmas do historicismo e sua peculiaridade consiste em ter usado como fonte de imitação as obras pregressas da arquitetura nacional. Trata-se, portanto, de um simples desvio de teorização internacional. Porém a singeleza deste fato haveria de ser de maiúscula importância no sentido da afirmaçăo do modernismo, seja por seu componente nacionalista, seja por sua integração na ideologia do estado e como instrumento de cooptação.

\section{O Historicismo e a Modernidade}

Segundo as teorizaçōes oficiais, o modernismo teria sido um rompimento radical com o passado, na medida em que teria substituldo as cópias inconseqüentes de um passado remoto pela criatividade em harmonia com as conquistas técnicas e com as aspiraçōes da nacionalidade.

Os dados, até aqui analisados, deixam claro que isto năo corresponde à realidade. $O$ historicismo foi o caminho pelo qual se processou uma atualizaçāo da arquitetura, por mais conservadores que fossem seus pressupostos. Partindo de uma concepção muito limitada de criatividade - a imitação da arte do passado - foi, paulatinamente ampliando este conceito de tal modo que no fim do século passado a concepção de arte já havia extrapolado totalmente as fronteiras do academismo: nāo havia ramo de produção material que não pudesse ser campo de experimentos artlsticos. Já não havia mais dúvidas de que o motor da inovação artistica era a criatividade.

Igualmente carece de fundamento a concepção de que a arte estivesse desvinculada de seu meio social. Através do exposto pretendeu-se demonstrar que, pelo contrário, as inovaçōes artisticas e construtivas foram uma das causas de uma lenta, mas segura, modernizaçăo da vida e dos processos de produção.

De tudo isto se percebe que o modernismo, na realidade, trouxe poucas inovaçōes e sua pretensa "revolução" consistiu apenas na conscientizaçāo de que a criatividade deveria entrar em sintonia com as técnicas modernas de construçăo que estavam em completa contradição com as formas históricas.

\section{Referências Bibliográficas}

BARATA, Mário. A arte no século XIX: do neoclassicismo e romantismo até o ecletismo. In: ZANINI, Walter. História geral da arte no Brasil. Sāo Paulo, Moreira Salles, 1983, p. 379-451, il.

BARDI, Pietro Maria. Arte no Brasil: uma história de cinco séculos. São Paulo, MASP, Catálogo de Exposiçāo, 1979.

BASTIDE, Roger. Brasil terra de contrastes. São Paulo, Difel, 1971, 284 p.

BENEVOLO, Leonardo. História da arquitetura moderna. Sāo Paulo, Perspectiva, 1976, 814 p. il.

BRUAND, Yves. Arquitetura contemporánea no Brasil. Sāo Paulo, Perspectiva, 1981, 400 p. il.

CARVALHO, Benjamin de Araujo. Duas arquiteturas no Brasil. Rio de Janeiro, Civilizaçāo Brasileira, 1961, 180 p. il.

CHANTAL, Suzanne. Portugal ao tempo do Terremoto. Lisboa, Livros do Brasil, 402 p. col. "A vida quotidiana" no 23, s.d.

ESTEVES, Alberto Joaquim. Igreja da Candelária. Rio de Janeiro, Imandade da Candelária, 1930, 44 p. il. 
HOLANDA, Sérgio Buarque de. Raßzes do Brasil. Rio de Janeiro, José Ollmpio, 1976, 154 p. 10 ed.

LEMOS, Carlos Alberto Cerqueira. Arquitetura brasileira. São Paulo, Melhoramentos, 1979, 158 p. il. - Alvenaria burguesa. São Paulo, Nobel, 1985, 196 p. il.

LÜTZELER, Heinrich. Vom sinn der Bauformen. (Sobre o significado das formas construldas). Freiburg, Herder, 1953, il.

MAURICIO, Augusto. Templos históricos de Rio de Janeiro. Rio de Janeiro, Laemmert, 1947, 312 p. il.

MELLO Jr., Donato. Antónlo José Landi, arquiteto de Belém. Belém, Governo do Parâ, 1973, 328 p. il.

MELLO, Eduardo Knesse de. Evolução da arquitetura no Brasil. Porto Alegre, Faculdade de Educação da UFRGS, 1983, Tema 11 (edição de diapositivos subdivididos em 13 temas, cada qual acompanhado de respectivo fasciculo), mimeo.

PAULA, Samuel de. Aspectos negativos da colonização portuguesa em confronto com a colonização anglo-saxónica. Rio de Janeiro, Paralelo, 1971, 108 p.

REIS Fㅇ, Nestor Goulart. Quadro da arquitetura no Brasil. São Paulo, Perspectiva, 1970, 214 p. il.

REIS Fo. Adolfo Morales de Los. Grandjean de Montigny e a evoluçáo da arte brasileira. Rio de Janeiro, Noite, 1941, 316 p. il.

SAIA, Luis. Morada paulista. São Paulo, Perspectiva, 1972, 316 p. il.

SANTOS, Paulo F. Quatro séculos de arquitetura. Rio de Janeiro, IAB, 1981, 1224 p.

WINCKELMANN, Johann Joachim. Reflexס̄es sobre a arte antiga. Porto Alegre, UFRGS/Movimento, 1975, 70 p. Tradução de CARO, Herbert; TOCHTROP, Leonardo. A $1^{\text {a }}$ edição em alemão é de 1755. 